\title{
How Does an Industry Thrive More From Exporting? A Theoretical Analysis of the Learning-by-Exporting Effect with Innovation and Asymmetric Demand
}

\author{
Ruohan Wu* \\ College of Business Administration, Alabama State University, Montgomery, AL, US \\ *Corresponding author: rwu@alasu.edu
}

Received January 19, 2014; Revised March 01, 2014; Accepted March 06, 2014

\begin{abstract}
This paper introduces asymmetric demand into an open-economy model. Domestic industries exhibit different export capabilities, and the export market attaches different preferences to them. My model shows how exports influence the market structure and productivity growth. If an industry exports more, the firms within the industry would face a higher domestic-market but lower export-market entry threshold. The industry can exhibit a significant learning-by-exporting effect; that is, its exports can significantly increase productivity growth, only when its innovation expenditure is sufficiently high.
\end{abstract}

Keywords: asymmetric demand, exports, productivity growth, learning-by-exporting, innovation

Cite This Article: Ruohan Wu, "How Does an Industry Thrive More From Exporting? A Theoretical Analysis of the Learning-by-Exporting Effect with Innovation and Asymmetric Demand." Journal of Finance and Economics, vol. 2, no. 2 (2014): 50-57. doi: 10.12691/jfe-2-2-2.

\section{Introduction}

Globalization produces both winners and losers. For example, computer manufacturing and related industries, such as electronic commerce services, or website hosting and software design, expanded during the late 20th century while other businesses such as manufacturers of primary products declined.

For a long time, economists have been trying to attribute these different growth outcomes to exporting activities. Old trade theory (e.g., the Heckscher-Ohlin model) focuses on comparative-advantage-driven trade between countries and excludes intra-industry trade for simplicity; new trade theory (e.g., Helpman and Krugman, 1985) focuses on preference for variety and increasing returns to scale, and does not consider differences across firms. Recently, the problem of heterogeneity has been frequently discussed. Generally, there are two classes of heterogeneous-firm theories: one was proposed by Bernard et al. (2003), who integrated firm productivity into a multi-country Ricardian model; the other was developed by Melitz (2003), who introduced heterogeneous productivity into Krugman's (1980) model. These theories explain how exports and productivity growth are related and how resources are reallocated across heterogeneous producers.

The positive correlation between exports and productivity growth has been well documented. On the one hand, high productivity is commonly regarded as the reason behind firms' export capability. Only when a firm is productive enough can it afford the expensive advertisement and shipment fees overseas. This argument, known as "self-selection theory" (Melitz, 2003; Bernard and Jensen, 2004), is supported by a large body of theoretical and empirical evidence. On the other hand, "learning-by-exporting theory" (Marin, 1992; Ben-David, 1993) argues that exports promote productivity growth. Export-market participation encourages access to more information, state-of-the-art technology, and better competition strategies and therefore greatly promotes industrial progress. Learning-by-exporting theory has so far encountered both positive and negative evidence. Studies based on manufacturers in Indonesia (Blalock and Gertler, 2004; Amiti and Konings, 2007), the UK (Girma et al., 2003, 2004), and Chile (Alvarez and López, 2005) have found significant production improvement after their entry into the export market. However, Clerides et al. (1998) use plant-level data from Mexico, Columbia, and Morocco but find no evidence that firms' costs can be reduced by exporting behaviors. Negative evidence against learning-by-exporting was also found among Swedish manufacturers (Greenaway et al., 2005).

People have been trying to resolve the conflicting evidence on learning-by-exporting theory. Using Canadian plant-level data, Lileeva et al. (2010) find that the learning effect occurs only when tariffs are cut to promote exports. Baldwin and Robert-Nicoud (2008) come up with a combined conclusion: trade liberalization improves industry productivity but it has an ambiguous effect on the productivity growth rate. It may even slow down industry growth by raising the expected innovation cost. Besides, many recent studies (Verhoogen, 2004; Costantini and Melitz, 2007; Aw et al., 2008; Bustos, 2011; Wu, 2013a,b) 
suggest that learning-by-exporting becomes possible through sufficiently high innovation investment.

This paper is motivated by the empirical evidence that export behavior exhibits asymmetric pattern. I then investigate how asymmetric exports influence an industry's structure. Similar methods have also been used in Burstein and Vogel (2009) to study resource reallocation among industries or even countries. This paper's main contribution is to introduce heterogeneous exports into the Melitz model and study how they lead to different growth paths. In traditional trade models, e.g., Krugman's theory, an open economy in two countries simply doubles an autarky; what happens to the home country mirrors the situation in the foreign country. An asymmetric market demand, on the contrary, explains the reality better. Furthermore, it successfully explains the mixed evidence for learning-by-exporting theory through innovation investment. Only those industries paying high enough for innovation can exhibit significant learning effects. This finding is consistent with the empirical evidence among US manufacturing industries.

The remainder of this paper is organized as follows. Section 2 explains the motivation. Section 3 presents an open economy model with asymmetric demand. Section 4 introduces the innovation consideration and provides the main results. Section 5 empirically examines the finding raised by section 4 .Section 6 concludes the paper.

\section{Motivation}

I start from presenting the stylized facts about asymmetric demand-in other words, how industrial products are distributed unevenly between the domestic and foreign markets.

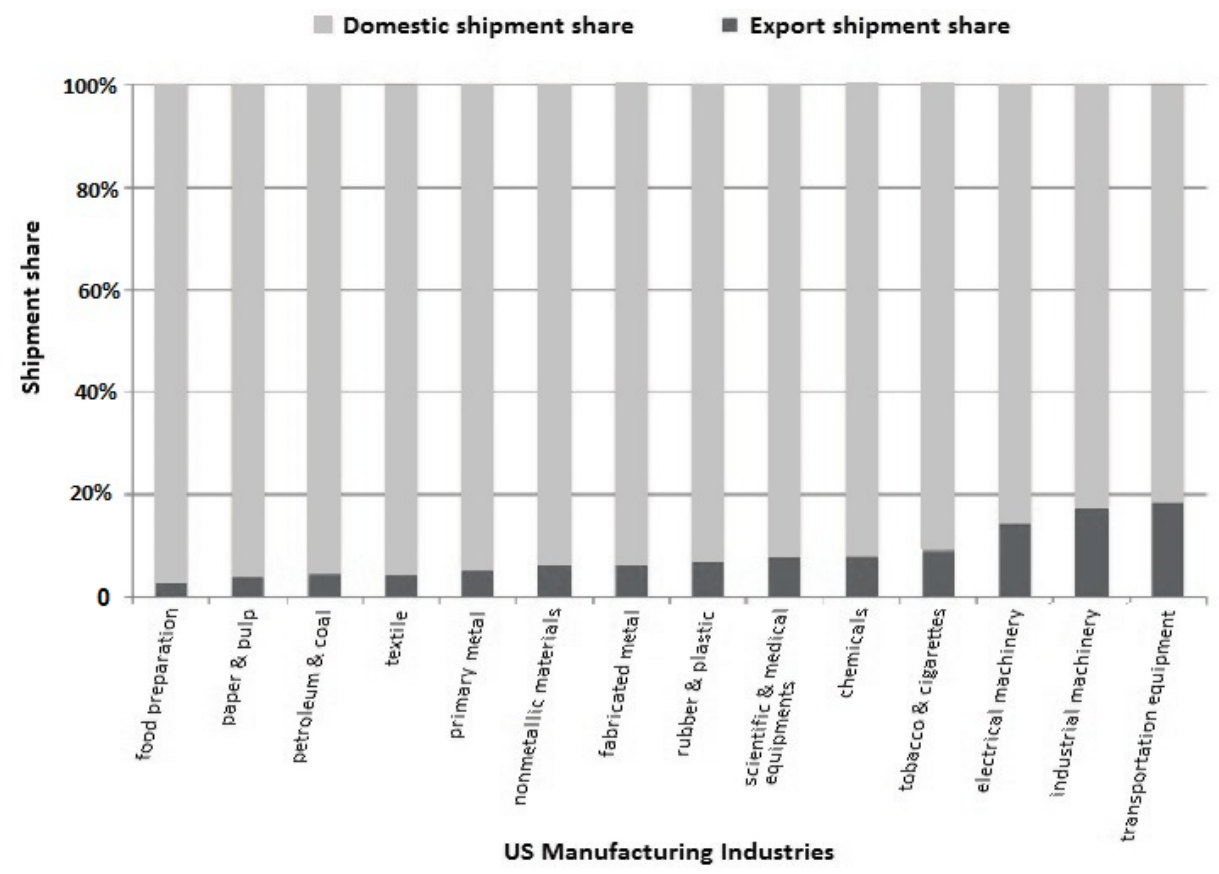

Figure 1. Comparison between US Domestic and Foreign Shipment Shares

Figure 1 is based on inputs from the Center for International Data at UC Davis and US Census's record of manufacturers' shipments, inventories, and orders. The figure compares domestic and export shipments across industries. The vertical axis measures the shares. The horizontal axis lists 14 US manufacturing industries. The majority of industrial shipments still flow into the domestic market. Even for the transportation-equipment industry, which has the highest export shipment share, over $80 \%$ of its products were sold domestically. Exporting behavior is still considerably rare. Furthermore, industries show very different export shares; e.g. electrical, industrial, or transportation equipment producers export much more than food and paper producers do. Compared with producers of primary materials, high-tech manufacturers can sell much more products overseas. Asymmetric demand does exist between domestic and foreign markets.

\section{Model}

Next I build a model to explain how exports can affect industrial structure. The model is an extension of Melitz's2003 framework. Only homogeneous labor is used in production.

\subsection{Demand}

We considerm industries, each indicated by $i \in\{1, \ldots, m\}$; industry $i$ has a continuum of goods $\omega \in \Omega_{i}$. The measure $\Omega_{i}$ represents all the available mass of productivity for industry $i$. The preference is then constructed by a constant elasticity of substitution (CES) utility function:

$$
Q_{i}=\left(\int_{\Omega_{i}} q_{i}(\omega)^{\eta} d \omega\right)^{\frac{1}{\eta}}
$$

where these goods are substitutes for each other and $0<\eta<1$, with an elasticity of substitution across industrial 
goods of $\frac{1}{1-\eta}>1$. This aggregator is associated with a price aggregator

$$
P_{i}=\left(\int_{\Omega_{i}} p_{i}(\omega) \frac{\eta}{\eta-1} d \omega\right)^{\frac{\eta}{\eta-1}}
$$

As originally shown by Dixit and Stiglitz (1977), the aggregators of preference and price across all industries are

$$
\begin{gathered}
Q=\left[\sum_{i=1}^{m} Q_{i}^{\varepsilon}\right]^{\frac{1}{\varepsilon}} \\
P=\left[\sum_{i=1}^{m} P_{i}^{\frac{\varepsilon-1}{\varepsilon}}\right]^{\frac{\varepsilon-1}{\varepsilon}}
\end{gathered}
$$

Here, the elasticity of substitution across industries is $\frac{1}{1-\varepsilon}{ }^{1}$. Based on these, we can easily have

$$
\begin{aligned}
\frac{q_{i t}(\omega)}{Q_{i t}} & =\left(\frac{p_{i t}(\omega)}{p_{i t}}\right)^{\frac{1}{\eta-1}} \\
\frac{Q_{i t}}{Q} & =\left(\frac{p_{i t}}{p}\right)^{\frac{1}{\varepsilon-1}}
\end{aligned}
$$

\subsection{Production}

A continuum of firms choose to produce a product variety $\omega$ acting as monopolistic competitorsagainst each other. With the index of productivity $\varphi$ in industry $i$, their production function is $q_{i}(\varphi)=\left(l_{i}(\varphi)-f\right) \varphi$, where each firm has a heterogeneous productivity level $\varphi$. Once a firm enters the market and starts production, it needs to pay a fixed cost $f$. Productivity $\varphi$ is drawn randomly from a common Pareto probability distribution function $g(\varphi)$ defined over $(0, \infty)$ with a continuous cumulative distribution $G(\varphi)=1-\left(\frac{\varphi L}{\varphi}\right)^{K}$. Meanwhile, following Krugman (1979), this production function leads to the pricing rule

$$
p_{i}(\varphi)=\frac{w}{\eta \varphi}
$$

Since labor is homogeneous with no high-and low-skill distinction, the wage rate $w$ is hereafter normalized to 1 . The revenue of a firm in industry $i$ is

$$
r_{i}(\varphi)=p_{i}(\varphi) q_{i}(\varphi)=\frac{q_{i}(\varphi)}{\eta \varphi}
$$

and its profit is

$$
\pi_{i}(\varphi)=r_{i}(\varphi)-l_{i}(\varphi)=(1-\eta) r_{i}(\varphi)-f
$$

\footnotetext{
${ }^{1}$ If $0<\varepsilon<1$, then the industrial products are substitutes; if $\varepsilon<0$, they are complements.
}

Before entry, firms are all identical. For a sunk initial investment, a firm gets a productivity $\varphi$. The sunk cost $F$ is a fixed entry cost. Both revenue and profit are functions of productivity. Once its $\varphi$ is revealed, the firm may decide whether to enter and export.

\subsection{Equilibrium under Autarky}

The $\varphi$ 'sare randomly drawn from $g(\varphi)$. Let $\varphi_{a}$ represent the productivity threshold for market entry, where the firm is indifferent between whether to enter or not. At this threshold, the profit is expected to be zero, and

$$
\begin{gathered}
\pi_{i}\left(\varphi_{i a}\right)=(1-\eta) r_{i}\left(\varphi_{i a}\right)-f=0 \\
r_{i}\left(\varphi_{i a}\right)=\frac{f}{1-\eta}
\end{gathered}
$$

Let us define the average aggregate productivity level in $i$ under an autarky circumstance as

$$
\tilde{\varphi}_{i a}=\tilde{\varphi}\left(\varphi_{i a}\right)=\left[\frac{1}{1-G\left(\varphi_{i a}\right)} \int_{\varphi_{i a}}^{\infty} \varphi^{\frac{\eta}{1-\eta}} d G(\varphi)\right]^{\frac{1-\eta}{\eta}}
$$

Following Melitz (2003), firms determine whether they should enter the market based on two conditions. The fist is a zero-cutoff-point condition (ZCP):

$$
\bar{\pi}_{i a}=\pi\left(\varphi_{i a}\right)=(1-\eta)\left(\frac{\tilde{\varphi}_{i a}}{\varphi_{i a}}\right)^{\frac{\eta}{1-\eta}} r_{i}\left(\varphi_{i a}\right)-f=\left(\left(\frac{\tilde{\varphi}_{i a}}{\varphi_{i a}}\right)^{\frac{\eta}{1-\eta}}-1\right) f
$$

The second is a free-entry (FE) condition on the zero expected entry value $v_{e}$ :

$$
\begin{gathered}
v_{e}=\left(1-G\left(\varphi_{\text {ia }}\right)\right) \sum_{t=0}^{\infty} \delta^{t} \pi\left(\tilde{\varphi}\left(\varphi_{\text {ia }}\right)\right)-F=0 \\
\tilde{\pi}_{i a}=\pi\left(\varphi_{\text {ia }}\right)=\frac{(1-\delta) F}{1-G\left(\varphi_{\text {ia }}\right)}
\end{gathered}
$$

Here, $\delta$ is the discount rate. As proved by Melitz (2003), only when a firm is productive enough can it enter the industry. In each industry $i$, there exists a market entry threshold $\varphi_{i a}>\varphi_{L}$ if and only if $\frac{\eta}{1-\eta}<k$ and $\frac{\frac{\eta}{1-\eta}}{k-\frac{\eta}{1-\eta}}>\frac{(1-\delta) F}{f}$, and only a firm with a productivity above this threshold can enter the market and start to produce. The proof is in Appendix B.1.

\subsection{Open Economy with Asymmetric Demand}

Assume that all the industries are export capable. As long as its productivity satisfies a certain condition, a firm can export. The foreign country has different preferences towards different industries. Specifically, the foreign demand is $q_{i}^{*}=\lambda_{i} q_{i}$. 
A preference coefficient $\lambda_{i}$ is introduced. A non-unit $\lambda_{i}$ indicates asymmetric demand between different markets; foreign buyers show specific preferences for each industry $i$. A bigger $\lambda_{i}$ indicates that industry $i$ 's products are preferred in the export market; therefore, $i$ is capable of exporting more.

A firm can start exporting only after it has already entered the domestic market. To export, firms not only face a per-unit cost (tariffs, transportation fees) but an initial fixed cost as well. The per-unit cost of each good is modeled according to the standard iceberg cost; in order that 1 unit of a product should arrive at the destination, $\tau>$ 1 units of the product must be shipped. Thus, $p_{i}^{*}(\varphi)=\tau p_{i}(\varphi)$. Exporting firms also need to pay a fixed export-market entry cost $f_{x}$. The export market, too, has a productivity threshold, and only firms above this threshold can export.

On the export market, the production function for goods demanded by the foreign country is $q_{i}^{*}=\left(l_{i}^{*}(\varphi)-f_{X}\right) \varphi$. A firm's export revenue is

$$
r_{i}^{*}(\varphi)=p_{i}^{*}(\varphi) \frac{q_{i}^{*}(\varphi)}{\tau}=\frac{\lambda}{\eta \varphi} q_{i}(\varphi)
$$

and labor used on export production is

$$
l_{i}^{*}(\varphi)=\frac{q_{i}^{*}(\varphi)}{\varphi}+f_{x}
$$

Therefore, the export profit is

$$
\pi_{i}^{*}(\varphi)=r_{i}^{*}(\varphi)-l_{i}^{*}(\varphi)=(1-\eta) r_{i}^{*}(\varphi)-f_{x}
$$

Similar to the autarky case, there is a domestic-market entry threshold $\varphi_{i e}$, and only a firm above this threshold can enter the market. To determine $\varphi_{i e}$, we also need two equilibrium conditions. Now, the ZCP condition for market entry is

$$
\bar{\pi}_{i}=\pi\left(\tilde{\varphi}\left(\varphi_{i e}\right)\right)+\frac{1-G\left(\varphi_{i x}\right)}{1-G\left(\varphi_{i e}\right)} \pi_{i}^{*}\left(\tilde{\varphi}\left(\varphi_{i x}\right)\right)
$$

while the FE condition is the same as in the autarky case:

$$
\pi_{i}=\pi\left(\tilde{\varphi}_{i e}\right)=\frac{(1-\delta) F}{1-G\left(\varphi_{i e}\right)}
$$

Proposition 1: Only when a firm is productive enough can it export. There exists a productivity threshold for domestic-market entry, $\varphi_{i e}>\varphi_{\text {ia }}$, and only a firm above this threshold can enter the domestic market and start production. There also exists a productivity threshold for export-market entry, $\varphi_{i x}$, and only a firm above this threshold can enter the export-market and start exporting. If and only if $\frac{f_{x}}{f}>\lambda_{i}$, the market is partitioned as $\varphi_{i x}>\varphi_{i e}$, and

$$
\varphi_{i x}=\varphi_{i e}\left(\frac{f_{x}}{f}\right)^{\frac{1-\eta}{\eta}} \lambda_{i}^{-\frac{1-\eta}{\eta}}
$$

Corollary 1: $\frac{\partial \varphi_{i e}}{\partial \lambda_{i}}>0, \frac{\partial \varphi_{i x}}{\partial \lambda_{i}}<0$

If an industry is capable of exporting more, its productivity threshold for domestic-market entry will also be higher. Meanwhile, its export-market entry threshold will be lower. Firms now face a higher standard to enter the market and start production. However, the productivity requirement for them to start exporting is lower. Consequently, the proportion of exporting firms will rise.

Furthermore, I use the weighted average productivity as an industry's aggregate productivity:

$$
\tilde{\varphi}_{i}=\tilde{\varphi}\left(\varphi_{i e}\right)=\left[\frac{1}{1-G\left(\varphi_{i e}\right)} \int_{\varphi_{i e}}^{\infty} \varphi^{\frac{\eta}{1-\eta}} d G(\varphi)\right]^{\frac{1-\eta}{\eta}}
$$

Since only those firms that have successfully entered the domestic market are considered active, this aggregator depends only on the domestic-market entry threshold.

\section{Innovation and Learning-by-Exporting Effect}

Based on the above static analysis of an open economy, I investigate the market structure of an industry. Next, I consider innovation. With increasing production and growth, manufacturers now have more opportunities to identify better strategies and advanced techniques. Moreover, they can develop better ideas on how to implement productivity-enhancing innovation.

Assume that in industry $i$, each firm can increase its current productivity from $\varphi$ to $\rho \varphi(\rho>1)$ by paying a fixed R\&D cost $\xi_{i}$. A firm not paying this cost will just keep its old productivity. With $\delta$ as the discount rate, a Bellman equation can be built:

$$
\begin{aligned}
V(\varphi) & =\max \left\{V_{\text {not innovate }}(\varphi), V_{\text {innovate }}(\varphi)\right\} \\
& =\max \{\pi(\varphi, \Theta)+\delta E V(\varphi), \pi(\rho \varphi, \Theta)+\delta E V(\rho \varphi)-\xi\}
\end{aligned}
$$

where $\Theta=\left\{\lambda_{i}, \tau, f, f_{X}, \eta, \varepsilon, \kappa, \varphi_{L}\right\}$. A firm makes its optimal decision according to its current given $\varphi$.

Proposition 2: The R\&D input $\xi_{i}$ determines which firms can innovate in each industry. If $\xi_{i}<(\rho-1) f$, all firms will innovate. If $(\rho-1) f<\xi_{i}<(\rho-1) f_{x}\left(1+\lambda_{i}^{-1}\right)$, there is a unique cutoff productivity $\varphi_{\text {in }} \in\left[\varphi_{i e}, \varphi_{i x}\right]$ so that all the exporting firms, as well as those domestic firms with $\varphi \in\left[\varphi_{\text {in }}, \varphi_{i x}\right)$, will innovate. If innovation costs $\xi_{i}>(\rho-1) f_{x}\left(1+\lambda_{i}^{-1}\right)$, there is a unique cutoff productivity $\varphi_{i n}^{*}>\varphi_{i x}$. Only those exporting firms with $\varphi>\varphi_{\text {in }}^{*}$ will innovate.

Last but not least, I examine how exports influence the aggregate productivity growth of an industry. For simplification, I focus on the growth rate $\Psi_{i}=\tilde{\varphi} \frac{\eta}{\varphi} 1-\eta$ : 


$$
\begin{gathered}
\dot{\Psi}_{i}=\frac{\Delta \Psi_{i}}{\Psi_{i}} \\
= \begin{cases}\frac{\rho-1}{1-G\left(\varphi_{i e}\right)} \int_{\varphi_{i e}}^{\infty} \varphi^{\frac{\eta}{1-\eta}} d G(\varphi) & \text { if } \xi_{i}<(\rho-1) f \\
\frac{\rho-1}{1-G\left(\varphi_{i e}\right)} \int_{\varphi_{i n}}^{\infty} \varphi^{\frac{\eta}{1-\eta}} d G(\varphi) & \text { if }(\rho-1) f<\xi_{i} \\
\frac{\rho-1}{1-G\left(\varphi_{i e}\right)} \int_{\varphi_{i n}^{*}}^{\infty} \varphi^{\frac{\eta}{1-\eta}} d G(\varphi) & \xi_{i}>(\rho-1) f_{x}\left(1+\lambda_{i}^{-1}\right)\end{cases}
\end{gathered}
$$

Corollary 2: The R\&D input $\xi_{i}$ determines when learning-by-exporting really takes effect. If $\xi_{i} \leq(\rho-1) f_{x}\left(1+\lambda_{i}^{-1}\right), \frac{\partial \dot{\Psi}_{i}}{\partial \lambda_{i}}=0$. Industrial productivity growth does not depend on exports. However, if $\xi_{i}>(\rho-1) f_{x}\left(1+\lambda_{i}^{-1}\right), \frac{\partial \dot{\Psi}_{i}}{\partial \lambda_{i}}>0 ;$ more exports can increase productivity growth. Only with sufficiently high innovation expenditure can an industry effectively increase its productivity growth through rising exports.

To sum up, exports and productivity influence each other. On the one hand, only more productive firms in a certain industry can manage to export. On the other hand, exports positively impact industrial productivity growth; however, this impact depends on innovation expenditure. Only when an industry sufficiently pays for innovation can it effectively learn from exporting.

\section{Empirical Evidence on Relationship between Export, Productivity Level, and Growth Rate}

Next I empirically examine the learning-by-exporting effect among the observed US industries. In Wu (2013a), using industry-level data of US manufacturers from 2005 to 2009, the learning-by-exporting effect is found to exist only when the industry's R\&D employment ratio is higher than 6\%; or its company-performed R\&D funds should be at least 5\%.Here I will examine whether this finding can also be supported by even earlier data. I use US export data from Feenstra (1997). The five-factor total-factorproductivity $\left(\mathrm{TFP}^{2}{ }^{2}\right.$ ) indicates industrial productivity; the information is based on the CES Manufacturing Industry Database (Bartelsman, Becker, and Gray 2000). I further divide the industries into different groups according to their innovation inputs, using data from National Science Foundation statistics, a summary dataset for R\&D performing companies in selected manufacturing and diverse nonmanufacturing industries: 1993 - 94. I divide the observed 433 manufacturing industries into three groups according to funds allocated to companyperformed R\&D: industries that spent less than $\$ 0.5$ billion, more than $\$ 0.5$ billion but less than $\$ 2$ billion, and

\footnotetext{
${ }^{2}$ TFP5 is based on a five-factor production function: capital $(K)$, production worker hours $(N)$, non-production worker hours $(L)$, nonenergy materials $(M)$, and energy ( $E)$. TFP5 $=Q-\sum_{n} a_{n} Y_{n}, n \in$ $\{K, N, L, M, E\} . Q$ is the real output, $\alpha_{n}$ is factor $n$ 's share in revenue, and $Y_{n}$ is the real input of $n$.
}

more than $\$ 8$ billion $^{3}$. They are included in group 1, group

\begin{tabular}{|c|c|c|c|c|c|}
\hline $\begin{array}{l}\text { independent } \\
\text { variable }\end{array}$ & $\begin{array}{l}\text { pooled } \\
\text { sample }\end{array}$ & $\begin{array}{l}\text { (1) } \\
\text { OLS }\end{array}$ & $\begin{array}{c}(2) \\
2 S L S\end{array}$ & remarks & N.Obs \\
\hline \multirow{4}{*}{$\begin{array}{c}\text { productivity } \\
\text { growth }\end{array}$} & $\begin{array}{c}\text { all } \\
\text { groups }\end{array}$ & $\begin{array}{c}0.34 \\
(0.11)\end{array}$ & $\begin{array}{c}0.43 \\
(0.38)\end{array}$ & $\begin{array}{l}\text { Effect of exports } \\
\text { on industrial } \\
\text { productivity } \\
\text { (TFP) }\end{array}$ & 433 \\
\hline & $\begin{array}{c}\text { group } \\
1\end{array}$ & $\begin{array}{c}1.52 \\
(2.24)\end{array}$ & $\begin{array}{c}-6.06 \\
(14.37)\end{array}$ & $\begin{array}{c}\mathrm{R} \& \mathrm{D} \\
\text { expenditure }< \\
\text { \$0.5 billion }\end{array}$ & 137 \\
\hline & $\begin{array}{c}\text { group } \\
2\end{array}$ & $\begin{array}{c}-0.28 \\
(0.58)\end{array}$ & $\begin{array}{c}-0.85 \\
(4.67)\end{array}$ & $\begin{array}{c}\$ 0.5 \text { billion }< \\
\text { R\&D } \\
\text { expenditure }< \\
\$ 2 \text { billion }\end{array}$ & 157 \\
\hline & $\begin{array}{c}\text { group } \\
3\end{array}$ & $\begin{array}{c}0.37^{* * *} \\
(0.10)\end{array}$ & $\begin{array}{c}0.41^{*} \\
(0.21)\end{array}$ & $\begin{array}{c}\text { R\&D } \\
\text { expenditure > } \\
\text { \$8 billion }\end{array}$ & 139 \\
\hline
\end{tabular}
2 , and group 3 , respectively.

Table 1. Learning-by-Exporting Effect among US Manufacturing Industries, 1994

Notes: $E_{i}$ is measured in $\$ 10^{11}$. Standard errors are reported in the parentheses.

*** Significant at or less than $1 \%$

** Significant at or less than $5 \%$.

* Significant at or less than $10 \%$.

The results are shown in Table 1 . To be specific, it reports all the $\beta$ s within

$$
\operatorname{DTFP}_{i}=E_{i} \beta+\varepsilon_{i}
$$

in the lower panel. DTFP5 is the annual growth rate of TFP5. $E_{i}$ indicates the exports per deflated shipment for each industry $i$. Column (1) reports all the OLS estimation results. If we do not consider $\mathrm{R} \& \mathrm{D}$ expenditure, exports significantly increase productivity levels but show no such impact on the productivity growth rate. In other words, the learning-by-exporting effect is not robust. However, after I group those industries, significant learning-by-exporting effect isfound only among those US manufacturing industries spending more than $\$ 8$ billion on R\&D. Only in group 3, within those industries spending the most for their R\&D activities, can we observe that more exports significantly accelerate productivity growth.

To remove potential endogeneity, I also use two-stage least-stage estimation (2SLS). The results are shown in Column (2) of Table 1. Tariff rates and deflated material costs are used as instrumental variables. I find the same results; only those industries with over $\$ 8$ billion $R \& D$ expenditure show significant learning-by-exporting effects.

\section{Conclusion}

Constructing an extended Melitz model with asymmetric demand, I study how exports can influence the market structure and industrial productivity growth. It turns out that if an industry has a higher export demand, its firms will face a higher market entry standard but a lower export threshold. Furthermore, the learning-byexporting effect depends on innovation expenditure. If this expenditure is sufficiently high, the industry will grow faster as it exports more. Otherwise, no significant learning-by-exporting effects can be observed.

Of course, there remain interesting extensions. For instance, this paper treats the home country as a small

${ }^{3}$ Interestingly, the data show a big gap in R\&D expenditure between $\$ 2$ billion and $\$ 8$ billion. No industries were found to spend between $\$ 2$ billion and \$8 billion on their R\&D activities in 1994 . 
economy by assuming the foreign demand to be given. Empirical support from small economies, e.g., Mexico, should be more convincing. To explain empirical evidence from US industries, a two-country model should be considered. In addition, one could extend the model by explicitly incorporating factor pricing. For simplicity, this paper assumes a unit wage. However, a varying wage would allow us to study its influence on firm- and industry-level growth, as well as the impacts of labor immigration and wage policies.

\section{References}

[1] Alvarez, R., and López, R., "Exporting and Performance: Evidence from Chilean Plants", Canadian Journal of Economics/Revue canadienne d'économique, 38(4): 1384-1400. 2005.

[2] Amiti, M. and Konings,J., "Trade Liberalization, Intermediate Inputs, and Productivity: Evidence from Indonesia.” The American Economic Review, 97(5): 1612-1638. 2007.

[3] Aw, B. Y., Roberts, M., and Xu,D. Y., "R\&D Investments, Exporting, and the Evolution of Firm Productivity", The American Economic Review, 98(2): 451-456. 2008.

[4] Baldwin, R. and Robert-Nicoud,F., "Trade and Growth with Heterogeneous Firms”, Journal of International Economics, 74(1): 21-34. 2008.

[5] Ben-David, D., "Equalizing Exchange: Trade Liberalization and Income Convergence", The Quarterly Journal of Economics, 108(3), 653-679. 1993.

[6] Bernard, A. and Jensen,B., "Exporting and Productivity in the USA”, Oxford Review of Economic Policy 20(3): 343-357. 2004.

[7] Bernard, A., Eaton, J., Jensen, B., and Kortum,S., "Plants and Productivity in International Trade", TheAmerican Economic Review, 1268-1290. 2003.

[8] Blalock G. and Gertler,P., "Learning from Exporting Revisited in a Less Developed Setting”,Journal of Development Economics 75(2): 397-416. 2004.

[9] Burstein, A. and Vogel,J., "Globalization, Technology, and the Skill Premium”, Columbia University working paper. 2009.

[10] Bustos, P., "Trade Liberalization, Exports, and Technology Upgrading: Evidence on the Impact of MERCOSUR on Argentinian Firms", The American Economic Review, 101(1): 304-340. 2011.

[11] Clerides, S., Lach,S., and Tybout,J., "Is Learning by Exporting Important? Micro-dynamic Evidence from Columbia, Mexico and Morocco”, TheQuarterly Journal of Economics, 113(3): 903-947. 1998.

[12] Costantini, J., andMelitz, M., “The Dynamics of Firm-Level Adjustment to Trade Liberalization”, The Organization of Firms in a Global Economy, 107-141. 2007.

[13] [13] Feenstra, R., "NBER Trade Database, Disk1: U.S. Imports, 1972-1994: Data and Concordances”, NBER Working Paper no. 5515. 1996.

[14] Girma, S., Greenaway,D., and Kneller,R., "Export Market Exit and Performance Dynamics: A Causality Analysis of Matched Firms”, Economic Letters, 80(2): 181-187. 2003.

[15] Girma, S., Greenaway,D., and Kneller,R., "Does Exporting Increase Productivity? A Microeconometric Analysis of Matched Firms”, Review of International Economics, 12(5): 855-866. 2004.

[16] Greenaway, D., Gullstrand, J., and Kneller, R., “Exporting may not always boost firm productivity”, Review of World Economics, 141(4): 561-582. 2005.

[17] Helpman, E., and Krugman., P., "Market Structure and Foreign Trade: Increasing Returns, Imperfect Competition and the International Economy”. The MIT press, Cambridge, 1985.

[18] Krugman, P.,"Scale Economics, Product Differentiation and the Pattern of Trade”, TheAmerican Economics Review, 70(5): 950959. 1980.

[19] Lileeva, A., andTrefler,D., "Improved Access to Foreign Markets Raises Plant-Level Productivity... for Some Plants", The Quarterly Journal of Economics,125(3): 1051-1099. 2010.

[20] Marin, D.,"Is the Export-Led Growth Hypothesis Valid for Industrialized Countries?”The Review of Economics and Statistics, 678-688. 1992
[21] Melitz, M.,"The Impact of Trade on Intra-Industry Reallocations and Aggregate Industry Productivity”, Econometrica, 71(6): 16951725. 2003.

[22] Verhoogen, E., “Trade, Quality Upgrading, and Wage Inequality in the Mexican Manufacturing Sector", The Quarterly Journal of Economics, 123(2): 489-530. 2008.

[23] Wu, R. "Reconsider Learning by Exporting Hypothesis from Innovation: An Empirical Study of US Industries", Journal of Business and Economics, 4(9): 804-816. 2013.

[24] Wu, R. "Empirically Revisiting the Learning-by-Exporting Theory Using Data on Chilean Manufacturing Plants”, Journal of Business Inquiry, forthcoming. 2013.

\section{Appendix}

\section{A. Relevant Variables / Parameters}

\begin{tabular}{|c|c|}
\hline Variables & Explanation \\
\hline$q_{i} / q_{i}^{*}$ & $\begin{array}{c}\text { Production of each firm in industry i sell to domestic } \\
\text { / export market }\end{array}$ \\
\hline$p_{i} / p_{i}^{*}$ & Domestic / Exporting price \\
\hline$l_{i} / l_{i}^{*}$ & $\begin{array}{l}\text { Units of labor input used to produce domestic / } \\
\text { export production }\end{array}$ \\
\hline$Q_{i}$ & Aggregate production of industry $i$ \\
\hline$P_{i}$ & Aggregate price of industry $i$ \\
\hline$Q$ & Aggregate production of all the industries \\
\hline$P$ & Aggregate price of all the industries \\
\hline$\pi_{i} / \pi_{i}^{*}$ & Profit from domestic / export market \\
\hline$r_{i} / r_{i}^{*}$ & Revenue from domestic / export market \\
\hline$\lambda_{i}$ & Industry i’s export preference \\
\hline$\varphi$ & Firm-level productivity \\
\hline$\varphi_{a}$ & Market entry threshold productivity in autarky \\
\hline$\varphi_{e}$ & $\begin{array}{c}\text { Domestic-market entry threshold productivity in } \\
\text { open economy }\end{array}$ \\
\hline$\varphi_{X}$ & $\begin{array}{l}\text { Export-market entry threshold productivity in open } \\
\text { economy }\end{array}$ \\
\hline$\varphi_{n}$ & Innovation cutoff productivity among domestic firms \\
\hline$\varphi_{n}^{*}$ & Innovation cutoff productivity among exporting firms \\
\hline$\tilde{\varphi}_{i}$ & Aggregate productivity of industry $i$ \\
\hline$\tau$ & Iceberg transportation cost \\
\hline$f / f_{x}$ & Fixed costs upon entering domestic / export market \\
\hline$\kappa, \varphi_{L}$ & Pareto productivity distribution parameters \\
\hline$\rho$ & Productivity growth rate upon innovation \\
\hline
\end{tabular}

\section{B. Proofs}

B.1:

As in Melitz (2003), define $k(\varphi)=\left(\frac{\tilde{\varphi}(\varphi)}{\varphi}\right)^{\frac{\eta}{1-\eta}}-1$, $j(\varphi)=[1-G(\varphi)] k(\varphi)=[1-G(\varphi)]\left[\left(\frac{\tilde{\varphi}(\varphi)}{\varphi}\right)^{\frac{\eta}{1-\eta}}-1\right]$, and the probability of entering domestic market under autarky is $p_{a}=1-G\left(\varphi_{a}\right)$, under an open economy is 
$p_{d}=1-G\left(\varphi_{e}\right)$ conditional on which the probability of exporting $p_{x}=\frac{1-G\left(\varphi_{x}\right)}{1-G\left(\varphi_{e}\right)}$. Next we need to solve the equation $j\left(\varphi_{a}\right)=\frac{(1-\delta) F}{f}$ and find whether it has only one root.

$$
j^{\prime}(\varphi)=\frac{d j(\varphi)}{d \kappa}=-\frac{1}{\varphi}(\sigma-1)[1-G(\varphi)][k(\varphi)+1]<0
$$

The left hand side (LHS) of the equation is monotonically decreasing and right hand side (RHS) is constant. What's more, in order to keep $\tilde{\varphi}$ always being finite, we need $\frac{\eta}{1-\eta}<\kappa$.

$$
\begin{gathered}
j\left(\varphi_{L}\right)=k\left(\varphi_{L}\right)=\frac{\int_{\varphi_{L}}^{\infty} \varphi^{\frac{\eta}{1-\eta}} d G(\varphi)}{\frac{\eta}{1-\eta}}-1=\frac{\frac{\eta}{1-\eta}}{\kappa-\frac{\eta}{1-\eta}} \\
\lim _{\varphi \rightarrow \infty} j(\varphi)=0 \\
\text { If and only if } \frac{\frac{\eta}{1-\eta}}{\kappa-\frac{\eta}{1-\eta}}>\frac{(1-\delta) F}{f} \text { can there be a }
\end{gathered}
$$

unique solution $\varphi(a) \in\left[\varphi_{L}, \infty\right]$.

\section{B.2: Proposition 1}

$$
\begin{gathered}
\frac{r^{*}\left(\varphi_{x}\right)}{r\left(\varphi_{e}\right)}=\lambda\left(\frac{\varphi_{x}}{\varphi_{e}}\right)^{\frac{\eta}{1-\eta}}=\frac{f_{x}}{f} \\
\frac{\varphi_{x}}{\varphi_{e}}=\lambda^{-\frac{\eta}{1-\eta}}\left(\frac{f_{x}}{f}\right)^{\frac{1-\eta}{\eta}}
\end{gathered}
$$

Based on the new ZCP condition and old FE condition, in order to find $\varphi_{i e}$ we will need to solve

$$
\begin{gathered}
\left(\left(\frac{\tilde{\varphi}_{e}}{\varphi_{e}}\right)^{\frac{1-\eta}{\eta}}-1\right) f+\frac{1-G\left(\varphi_{x}\right)}{1-G\left(\varphi_{e}\right)}\left(\left(\frac{\tilde{\varphi}_{e}}{\varphi_{e}}\right)^{\frac{1-\eta}{\eta}}-1\right) f_{x=\frac{(1-\delta) F}{1-G\left(\varphi_{e}\right)}} \\
j\left(\varphi_{e}\right)+j\left(\varphi_{x}\right) \frac{f_{x}}{f}=\frac{(1-\delta) F}{f}
\end{gathered}
$$

The LHS is decreasing with respect to $\varphi_{e}$, since $j(\varphi)>0, \frac{d j\left(\varphi_{e}\right)}{d \varphi_{e}}<0, \frac{\partial j\left(\varphi_{x}\right)}{\partial \varphi_{X}}=\frac{\partial j\left(\varphi_{x}\right)}{\partial \varphi_{X}} \frac{\partial \varphi_{x}}{\partial \varphi_{e}}<0$. There is only one $\varphi_{e}$ existing. At $\varphi_{e}$ the LHS will meet with the RHS, which is a horizontal line, still from the above but in a higher position compared to the autarky case in B.1.
Specifically, let $J\left(\varphi_{e}\right)=j\left(\varphi_{e}\right)+j\left(\varphi_{x}\right) \frac{f_{x}}{f} \quad$ as a decreasing function of $\varphi_{e}$,

$$
\begin{gathered}
J\left(\varphi_{a}\right)>j\left(\varphi_{a}\right)=J\left(\varphi_{e}\right) \\
\varphi_{a}<\varphi_{e} \\
J(\infty)=j(\infty) \frac{f_{x}}{f}=0
\end{gathered}
$$

Therefore a $\varphi_{e}>\varphi_{a}$ exists. As for $\varphi_{e}<\varphi_{x}$, it is consistent with the timing assumption. Only those firms who have entered the market can have the chance to update; there is no firms exporting to the foreign market while not producing domestically.

\section{B.3: Corollary 1}

Let $\zeta=\lambda^{-\frac{1-\eta}{\eta}}$, so that $\varphi_{x}=\varphi_{e}\left(\frac{f_{x}}{f}\right)^{\frac{1-\eta}{\eta}} \zeta$.

Take derivatives with respect to $\zeta$ on both sides of (25):

$$
j^{\prime}\left(\varphi_{e}\right) \frac{\partial \varphi_{e}}{\partial \zeta}+j^{\prime}\left(\varphi_{X}\right) \frac{\partial \varphi_{X}}{\partial \zeta} \frac{f_{X}}{f}=0
$$

Since $\frac{\partial \varphi_{x}}{\partial \zeta}=\frac{\varphi_{x}}{\zeta}+\frac{\varphi_{x}}{\varphi_{e}} \frac{\partial \varphi_{e}}{\partial \zeta}$

$$
f j^{\prime}\left(\varphi_{e}\right) \frac{\partial \varphi_{e}}{\partial \zeta}+f_{x} j^{\prime}\left(\varphi_{x}\right)\left(\frac{\varphi_{x}}{\zeta}+\frac{\varphi_{x}}{\varphi_{e}} \frac{\partial \varphi_{e}}{\partial \zeta}\right)=0
$$

$$
\begin{gathered}
\frac{\partial \varphi_{e}}{\partial \zeta}=-\frac{f_{x} \frac{j^{\prime}\left(\varphi_{x}\right) \varphi_{x}}{\zeta}}{f j^{\prime}\left(\varphi_{e}\right)+f_{x} j^{\prime}\left(\varphi_{x}\right) \varphi_{x} / \varphi_{e}} \\
=-\frac{\varphi_{e}}{\zeta} \frac{f_{x} j^{\prime}\left(\varphi_{x}\right) \varphi_{x}}{f j^{\prime}\left(\varphi_{e}\right) \varphi_{e}+f_{x} j^{\prime}\left(\varphi_{x}\right) \varphi_{x}}<0 \\
\frac{\partial \varphi_{x}}{\partial \zeta}=-\frac{f}{f_{x}} \frac{j^{\prime}\left(\varphi_{e}\right)}{j^{\prime}\left(\varphi_{x}\right)} \frac{\partial \varphi_{e}}{\partial \zeta}>0
\end{gathered}
$$

\section{B.4: Proposition 2}

$(\rho-1) f_{X}\left(1+\lambda^{-1}\right)=(\rho-1) f \frac{f_{X}}{f}\left(1+\lambda^{-1}\right)>(\rho-1) f$

If $\xi>(\rho-1) f_{X}\left(1+\lambda^{-1}\right)$, the innovation decision Bellman equation is

$$
\begin{aligned}
V(\varphi) & =\max \left\{V_{\text {not innovate }}(\varphi), V_{\text {innovate }}(\varphi)\right\} \\
& =\max \left\{\left(\left(\frac{\varphi}{\varphi_{e}}\right)^{\frac{1-\eta}{\eta}}-1\right) f+\delta V(\varphi),\left(\left(\frac{\rho \varphi}{\varphi_{e}}\right)^{\frac{1-\eta}{\eta}}-1\right) f+\delta V(\rho \varphi)-\xi\right\}
\end{aligned}
$$

At $\varphi=\varphi_{n}$, we have

$F_{1}\left(\varphi_{n}\right)=V_{\text {not innovate }}-V_{\text {innovate }}$

$=\left(\frac{\rho \varphi_{n}}{\varphi_{e}}\right)^{\frac{1-\eta}{\eta}} f-\left(\frac{\varphi_{n}}{\varphi_{e}}\right)^{\frac{1-\eta}{\eta}} f-\xi=(\rho-1) f\left(\frac{\varphi}{\varphi_{e}}\right)^{\frac{1-\eta}{\eta}}-\xi$ 
Since $\frac{\partial F_{1}}{\partial \varphi_{n}}>0 \quad, \quad F_{1}\left(\varphi_{e}\right)=(\rho-1) f-\xi<0$, $F_{1}\left(\varphi_{i x}\right)=(\rho-1) f_{X} \lambda^{-1}-\xi<0 . \varphi_{n}>\varphi_{X} ;$ no cutoff productivity $\varphi_{n} \in\left[\varphi_{e}, \varphi_{x}\right)$ exists for domestic firms, non of them will innovate.

For exporting firms, the innovation decision Bellman equation is

$$
\begin{aligned}
V(\varphi)=\max & \left\{\left(\left(\frac{\varphi}{\varphi_{e}}\right)^{\frac{1-\eta}{\eta}}-1\right) f+\lambda\left(\frac{\varphi}{\varphi_{e}}\right)^{\frac{1-\eta}{\eta}} f-f_{x}+\delta V(\varphi),\right. \\
& \left.\left(\left(\frac{\rho \varphi}{\varphi_{e}}\right)^{\frac{1-\eta}{\eta}}-1\right) f+\lambda\left(\frac{\rho \varphi}{\varphi_{e}}\right)^{\frac{1-\eta}{\eta}} f-f_{x}+\delta V(\rho \varphi)-\xi\right\}
\end{aligned}
$$

At $\varphi=\varphi_{n}^{*}$, we have

$$
\begin{aligned}
F_{2}\left(\varphi_{n}^{*}\right) & =V_{\text {not innovate }}-V_{\text {innovate }} \\
& =\left(\frac{1+\lambda}{\frac{1-\eta}{\varphi_{e}}}\right)(\rho-1) f \varphi_{n}^{* \frac{1-\eta}{\eta}}-\xi \\
& =(\rho-1) f\left(\frac{\varphi_{n}}{\varphi_{e}}\right)^{\frac{1-\eta}{\eta}}-\xi \\
& =0
\end{aligned}
$$

Since $\frac{\partial F_{2}}{\partial \varphi_{n}^{*}}>0, F_{2}\left(\varphi_{X}\right)=(\rho-1) f_{X}\left(1+\lambda^{-1}\right)-\xi<0$, $F_{2}(\infty)=\infty$, thus a unique cutoff productivity $\varphi_{n}^{*}>\varphi_{X}$ exists for exporting firms.

If

$$
(\rho-1) f<\xi<(\rho-1) f_{x}\left(1+\lambda^{-1}\right)
$$

$0<F_{2}\left(\varphi_{x}\right)<F_{2}(\infty), \varphi_{n}^{*}<\varphi_{x}$. All the exporting firms innovate because the cost is low. Meanwhile, $F_{1}\left(\varphi_{e}\right)<0$, $F_{1}\left(\varphi_{X}\right)>0$; still, $F_{1}$ is increasing with $\varphi_{n}$, thus a unique $\varphi_{n} \in\left[\varphi_{e}, \varphi_{X}\right)$ exists. $\frac{\partial F_{1}}{\partial \lambda}=\frac{\partial F_{1}}{\partial \varphi_{e}} \frac{\partial \varphi_{e}}{\partial \lambda}<0$, therefore $\frac{\partial \varphi_{n}}{\partial \lambda}>0$

If $(\rho-1) f>\xi, F_{1}\left(\varphi_{e}\right)>0, F_{2}\left(\varphi_{X}\right)>0$. Now $\varphi_{n}<\varphi_{e}$ and $\varphi_{n}^{*}<\varphi_{x}$. All the firms will innovate. 